\title{
LITHOPTYSIS ASSOCIATED WITH CHRONIC PULMONARY TUBERCULOSIS
}

\author{
K. Radha Rani ${ }^{1}$, B. Sarada ${ }^{2}$, N. Krishnaveni ${ }^{3}$
}

\section{HOW TO CITE THIS ARTICLE:}

K. Radha Rani, B. Sarada, N. Krishnaveni. "Lithoptysis associated with Chronic Pulmonary Tuberculosis". Journal of Evolution of Medical and Dental Sciences 2014; Vol. 3, Issue 72, December 22; Page: 15331-15336,

DOI: $10.14260 /$ jemds/2014/4065

ABSTRACT: OBJECTIVE: A case of lithoptysis i.e., coughing out calcified material is reported, showing a rare aspect of peribronchial calcified tuberculous lymphadenopathy, eroding bronchial wall and resulting in lithoptysis. The Clinical, Pathological and Radiological importance in diagnosing and assessment of disease with emphasis on Spiral CT scan as important imaging modality is discussed. Infection by Mycobacterium tuberculosis followed by Histoplasma capsulatum is currently the main causes of broncholithiasis resulting in lithoptysis².

KEYWORDS: Lithoptysis, broncholith, spiral CT, pulmonary tuberculosis, bronchoscopy.

INTRODUCTION: Lithoptysis was first described by Aristotle, 300 years BC3. It is characterized by peribronchial, hilar or parenchymal calcifications slowly eroding the bronchial wall into bronchial lumen and resulting in lithoptysis, haemoptysis or symptoms related to bronchial obstruction may occur. Under these circumstances careful attention should be paid to the evidence of position, number and movement of calcific focus and its relationship to the bronchi ${ }^{4}$.

Common infectious etiologies are Tuberculosis, Histoplasmosis ${ }^{5}$ and other causes are Silicosis, Sarcoidosis, Ciliary diskiniasis ${ }^{2}$ and Chronic bronchiectasis.

The present authors report a rare case of lithoptysis in elderly male with a known case of old pulmonary tuberculosis presenting at chest OPD, bringing with him coughed out calcified material. Chest X-ray and CT chest revealed calcified mediastinal, peribronchial, Hilar calcified nodes and parenchymal fibro-calcific lesions.

CASE REPORT: A 65 years old male patient presented in chest OPD complaining of sudden bout of cough followed by expelling of hard pellets and red streaky sputum.On examination, his general condition is stable. His previous history revealed treatment with ATT for pulmonary Koch's 5 years back. At present he is taking only symptomatic treatment for dry cough.

The X-ray chest PA and Lateral views (Fig-1a, b) revealed fibrocalcific lesions with haziness in both mid and upper zones with multiple calcific lesions in both hilar and perihilar regions and blunting of both costophrenic angles suggestive of Pulmonary Koch's with calcified lymphadenopathy and associated pleural pathology.

Spiral CT chest (Fig-2a, b, c) was performed with findings of multiple paratracheal, tracheobronchial, hilar, carinal and peribronchial calcified lesions of variable sizes, situated closely to bronchial lumen, suggestive of calcified lymphadenopathy associated with fibrocalcific lesions and parenchymal infiltrations with bronchiectasis changes in both upper and middle lobes with minimal left pleural effusion - features suggestive of Chronic pulmonary tuberculosis.

The past history of pulmonary tuberculosis and treatment by ATT 5years back, the above X ray chest and CT chest findings and in view of endemicity of pulmonary tuberculosis in our region, the present symptom of lithoptysis is attributed to sequelae of chronic pulmonary tuberculosis. 


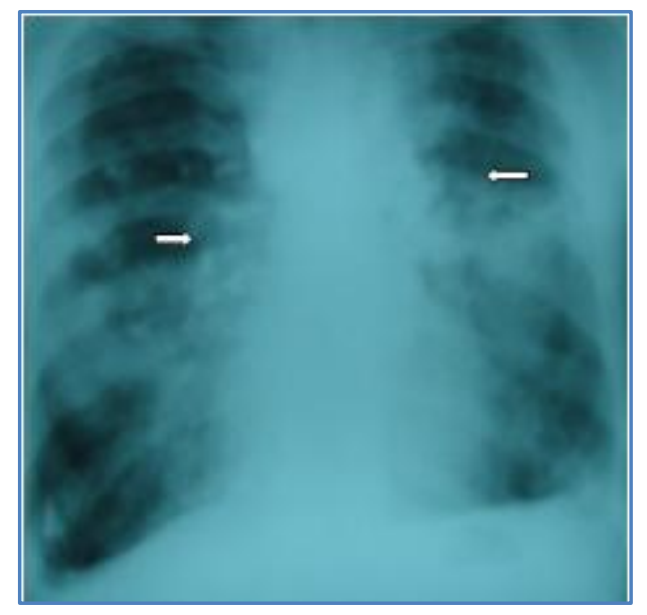

Fig. 1(a): X - ray Chest PA view

Multiple calcified lesions in both para tracheal, Tracheo-bronchial and hilar regions (arrows), both lung fields show haziness and Fibro-calcific lesions. Blunting of both cp angles.

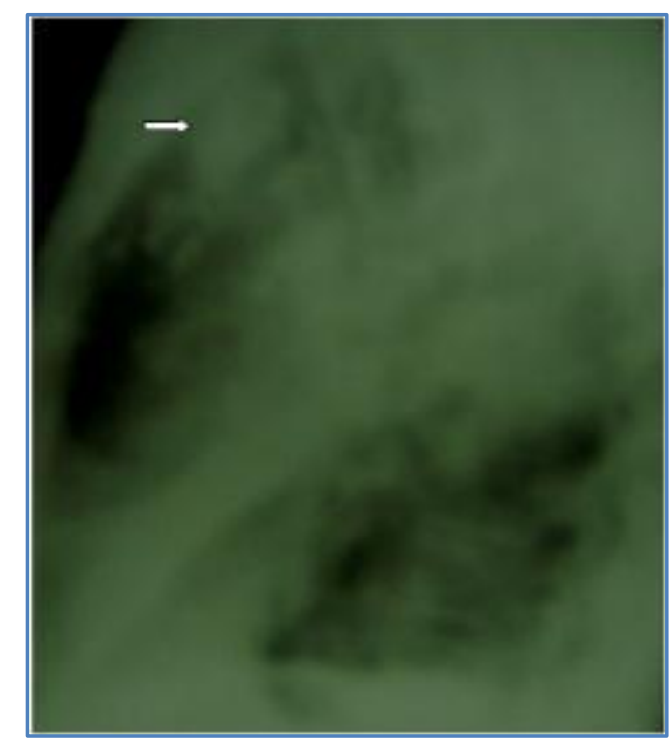

Fig. 1(b): X - ray Chest lateral view

Multiple calcified lesions in both para tracheal Tracheo-bronchial, and hilar regions (arrows), both lung fields show haziness and Fibro-calcific lesions and blunting of $\mathrm{cp}$ angles. 


\section{CASE REPORT}

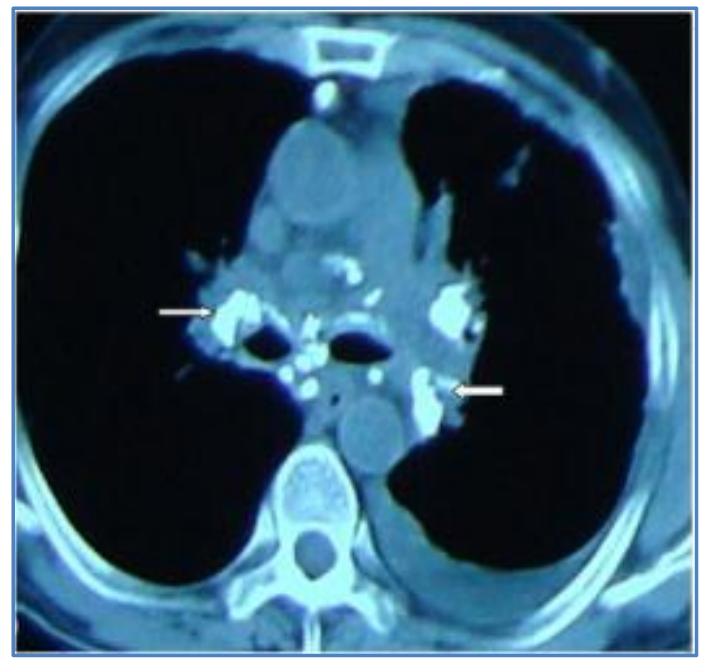

\section{Fig. 2(a): CT chest axial view (mediastinal window)}

Multiple calcific densities in carinal and both hilar regions (arrows) Pleura shows irregular thickening and minimal Lt pleural effusion.

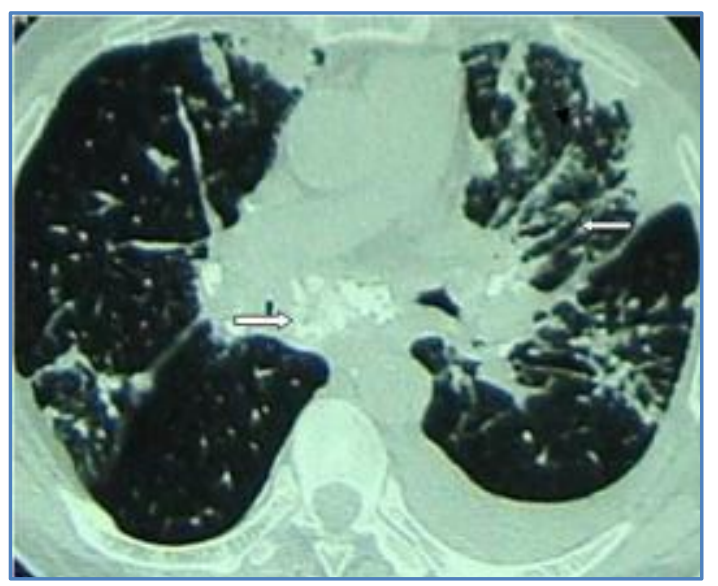

\section{Fig. 2(b): CT chest (lung window)}

Multiple calcified densities In carina \& hilar regions. Lung parenchyma shows bilateral fibrotic lesions and parenchymal calcifications (arrows). 


\section{CASE REPORT}

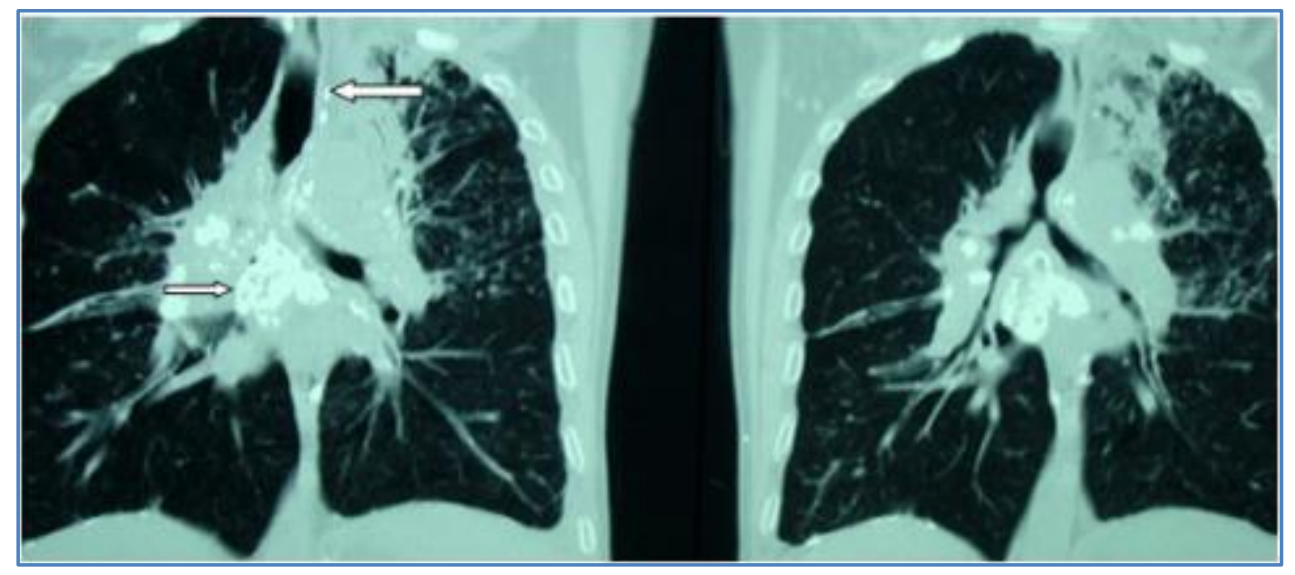

Fig. 2(c)

Fig. 2(c): CT chest coronal image, Lung Window - Calcified densities in paratracheal, tracheobronchial, carinal, \& hilar regions (arrows) in relation to airways clearly depicted.

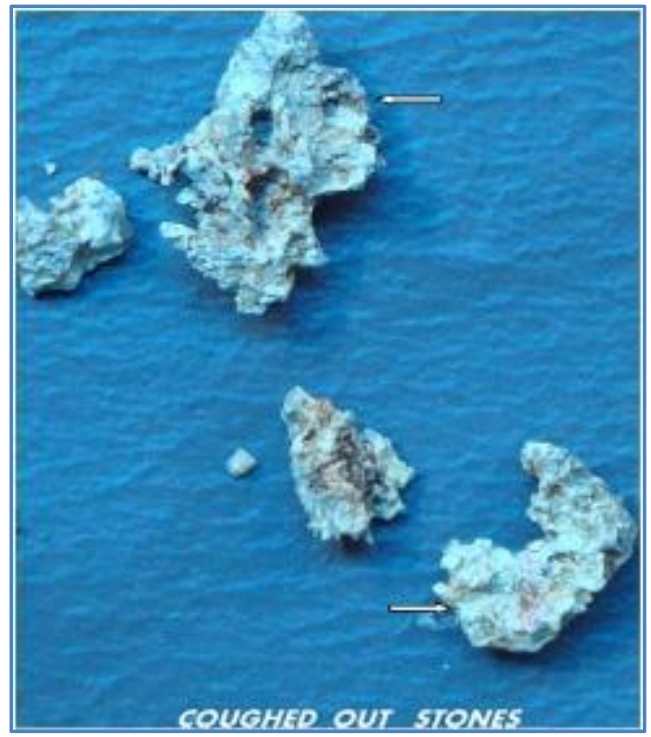

Fig. 3: Gross specimen of coughed out stones

DISCUSSION: Lithoptysis is a condition in which erosion and extrusion of calcified peribronchial lymph nodes into the lumen (Broncholith), which is associated with necrotizing granulomatous lymphadenitis. The clinical symptoms most common are chronic cough, fever, haemoptysis and chest pain and rarely lithoptysis. The incidence of lithoptysis is $15-26 \%$.

The important radiological investigations are Plain X ray Chest PA and Lateral views and HRCT/Conventional CT chest. X-ray Chest revealed calcified lesions both in mediastinum and lung parenchyma and fibrocalcific lesions in lung fields, but failed to show the exact location of calcifications in relation to the bronchus. 


\section{CASE REPORT}

Spiral CT is the modality of choice and proves the relationship of tracheo- bronchial tree to the calcified nodes and number of calcifications and also reveals other associated findings like atelectasis, obstructive pneumonia, bronchiectasis and Koch's lesions. Soft tissue lesions and malignancy can be ruled out. Difficulty in determining the relationship between lymph node and the bronchus is due to volume averaging, which can be decreased by scanning with thinner sections. 6,7

Bronchoscopy is useful to locate and extract broncholiths, but fails to detect adjacent calcifications because it is obscured by the inflammatory process.

As in our case, with a known clear history and findings of pulmonary tuberculosis we can suffice the investigations with single important imaging modality i.e., C T chest.

Other differential diagnosis are endobronchial infections, calcified fungal balls, endobronchial fungal infections, 6,7 calcified endobronchial tumours, tracheo-bronchial diseases with mural calcifications (Amyloidosis), hypertrophied bronchial artery with intraluminal protrusion. The complications are rarely bronchoesophageal or bronchoaortic fistulas.

The prognosis for lithoptysis is typically favourable and its treatment depends on the clinical picture.

Use of invasive examination and treatment methods depends on locating the stones, its size and associated complications. Surgery or bronchoscopic extraction is recommended in selected cases.

\section{REFERENCES:}

1. Collins J, Stern EJ. Chest radiology, the essentials. Lippincott Williams \& Wilkins. (2007), ISBN: 0781763142.

2. Francisco Roig Va'zquez, Emilio Ansotegui Barrera, Jose Manuel Martinez Albiach Lithoptysis in a Patient with Primary Ciliary Dyskinesia. Arch Bronconeumol. 2002 Aug; 42(8)417. PMID: 16948997.

3. Faber LP, Jensik RJ, Chawla SK, Kittle CF. The Surgical Implication of Broncholithiasis. J Thorac Cardiovasc Surg. 1975; 70: 778-89.

4. Vernon A. Vix M. D., Radiographic Manifestations of Broncholithiasis. Radiology. 1978 Aug; 128(2): 295-9.Pubmed PMID: 663233.

5. Freedman E, Billings J. H. Active bronchopulmonary lithiasis. Radiology 1949; 53: 203-215.

6. Conces D. J Jr, Tarver RD, Vix VA. Broncholithiasis: CT features in 15 patients. AJR Am J Roentgenol 1991; 157: 249-253.

7. J. B. Seo, Koun-Sik Song, J. S Lee, J. M Goo, H. Y Kim, Jae-Woo Song, I. S Lee, and Tae-Hwan Lim. Broncholithiasis: Review of the Causes with Radiologic-Pathologic Correlation. Radiographics 2002; 22: S199-S213. 


\section{CASE REPORT}

\section{AUTHORS:}

1. K. Radha Rani

2. B. Sarada

3. N. Krishnaveni

\section{PARTICULARS OF CONTRIBUTORS:}

1. Associate Professor, Department of Radio-Diagnosis, Government General Hospital, Government Medical College, Ananthapuramu.

2. Assistant Professor, Department of RadioDiagnosis, Government General Hospital, Government Medical College, Ananthapuramu.

3. Professor and Head, Department of Radio-Diagnosis, Government General Hospital, Government Medical College, Ananthapuramu.

\section{NAME ADDRESS EMAIL ID OF THE} CORRESPONDING AUTHOR:

Dr. Radha Rani K,

D. No. 11-127-6-4,

Government Medical College

Staff Quarters, Besides Jesus Nagar

Power Office, Ananthapuramu - 515001, Andhra Pradesh.

Email: drradharanikaki@gmail.com

Date of Submission: 24/11/2014. Date of Peer Review: 25/11/2014. Date of Acceptance: 16/12/2014. Date of Publishing: 22/12/2014. 